\title{
Community-acquired necrotizing pneumonia due to methicillin-sensitive Staphylococcus aureus secreting Panton-Valentine leukocidin: a review of case reports
}

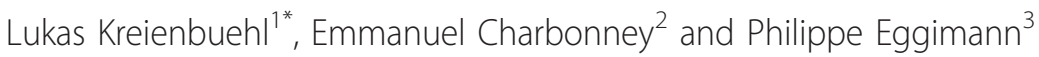

\begin{abstract}
Background: Community-acquired necrotizing pneumonia caused by Panton-Valentine leukocidin (PVL)-secreting Staphylococcus aureus is a highly lethal infection that mainly affects healthy children and young adults. Both methicillin-sensitive S. aureus (MSSA) and methicillin-resistant S. aureus (MRSA) may carry the PVL-phage, but the majority of publications relate to community-associated methicillin-resistant $S$. aureus (CA-MRSA) or mixed patient groups. This study focuses on necrotizing pneumonia due to methicillin-sensitive S. aureus strains, with the purpose to determine factors associated with outcome.

Methods: We report a patient with PVL secreting MSSA necrotizing pneumonia and performed a systematic review of similar case in the literature. We analyzed factors associated with outcome.

Results: A total of 32 patient descriptions were retained for analysis. Septic shock ( $p=0.007$ ), influenza-like prodrome $(p=0.02)$, and the absence of a previous skin and soft-tissue infection $(p=0.024)$ were associated with fatal outcome. In multivariate analysis, influenza-like prodrome (odds ratio (OR), 7.44; $95 \%$ confidence interval (Cl), 1.24-44.76; $p=0.028)$ and absence of previous skin and soft-tissue infection $(\mathrm{OR}, 0.09 ; 95 \% \mathrm{Cl}, 0.01-0.86 ; p=0.036)$ remained significant predictors of death.
\end{abstract}

Conclusions: Influenza-like prodrome may be predictive of adverse outcome in PVL-secreting MSSA necrotizing pneumonia. In contrast, previous skin and soft-tissue infection may be associated with improved prognosis.

\section{Background}

Staphylococcus aureus is estimated to cause $1-10 \%$ of community acquired pneumonias (CAP) and $20-50 \%$ of nosocomial pneumonias [1]. It is an important factor of influenza-related morbidity and mortality and approximately half of the patients with $S$. aureus pneumonia have underlying comorbidities and risk factors [2,3]. In 1999, Lina et al. found an association between necrotizing pneumonia and Panton-Valentine leukocidin (PVL)secreting S. aureus [4]. In 2002, Gillet et al. defined the clinical features of PVL-associated necrotizing pneumonia, followed in 2007 by the description of risk factors

\footnotetext{
* Correspondence: lukas.kreienbuehl@hcuge.ch

'Department of Anaesthesiology, Hôpitaux Universitaires de Genève (HUG), Geneva, Switzerland

Full list of author information is available at the end of the article
}

associated with mortality $[5,6]$. PVL is thought to be a key factor in the pathogenesis of necrotizing pneumonia. It forms pores in the cell and mitochondrial membrane of neutrophils and macrophages and thus provokes cell lysis and apoptosis with subsequent liberation of inflammatory mediators $[4,7]$. Some authors contest the pathogenic potential of PVL and suggest the presence of PVLgenes to be a marker of other virulence determinants $[8,9]$.

The global distribution of PVL-carrying S. aureus varies geographically. In North America, the most dominant clone is ST8-USA300, which is responsible for the majority of community-associated methicillin-resistant $S$. aureus MRSA (CA-MRSA)-related infections [10,11]. European isolates are more commonly methicillin-sensitive $S$. aureus (MSSA) [4,6]. Overall, the prevalence of 
PVL-carrying $S$. aureus seems to be increasing. A U.S. wide study examining the proportion of CA-MRSA among S. aureus CAP during the 2006-2007 influenza seasons found a prevalence of $79 \%$, in contrast to $12 \%$ between 1986 and 2005 [3]. The Health Protection Agency Staphylococcus Reference Unit (HPA-SRU) in England recorded a steady increase of PVL-positive $S$. aureus between 2005 and 2009, with a majority of strains being methicillin-sensitive $(61.5 \%$ versus $38.5 \%$ in 2010) [12]. Molecular profiles of methicillin-sensitive and methicillin-resistant PVL-carrying $S$. aureus reveal close genetic similarity and the former are thought to constitute a reservoir for the latter [13].

Current knowledge about clinical features and mortality of PVL-positive $S$. aureus necrotizing pneumonia is based on series and case reports. The typical clinical picture is a previously healthy child or young adult with an influenza-like prodrome, who rapidly develops septic shock and respiratory failure, in the context of multilobar consolidation, pleural effusion, and airway hemorrhage [5]. Influenza-like prodrome, leuko- and thrombocytopenia, airway hemorrhage, and pleural effusion are considered predictive of fatal outcome [6]. Published mortality rates vary between $40 \%$ and $60 \%$ $[3,6,14,15]$. One study compared outcome between MSSA and MRSA strains, without finding a significant difference [14].

We report a patient with PVL-secreting MSSA-necrotizing pneumonia, who had a classical clinical presentation and was successfully treated with antitoxin antibiotics and intravenous immunoglobulin. He was included in a review and analysis of clinical characteristics of reported patients with a PLV-positive methicillinsensitive $S$. aureus necrotizing pneumonia, with the goal to confirm outcome factors.

\section{Methods}

We searched for case reports and case series about PLV-positive MSSA-community-acquired pneumonias published before April 2010, using PubMed, with the search terms "community-acquired pneumonia," "necrotizing pneumonia," and "Panton-Valentin leukocidin." The reference sections of case reports, case series, and relevant research and review articles were scanned for missed case reports and case series. Case series, which lacked individual clinical patient descriptions, were excluded. Only articles in English, French, and German were analyzed. The patient treated in our own institution was included in the analysis. The extracted clinical, microbiological, and outcome data were converted into variables and analyzed accordingly. For continuous variables, results are summarized as mean \pm SD and categorical variables are expressed in proportions. Fisher's exact test and Student's $t$ test were used for categorical and continuous variables, respectively. Variables significantly associated with outcome in the univariate analysis were included in a multivariable model. For all tests, a two-tailed $P$ value $<0.05$ was considered to denote statistical significance. Data analysis was performed with SAS 9.2 (SAS Institute Inc.: Cary, NC, USA).

\section{Case report}

A 32-year-old, previously healthy, Caucasian male presented with severe sepsis and acute respiratory failure. In the previous week, he noted an influenza-like illness. On examination, chest auscultation revealed discrete inspiratory crackles over the lower lung fields. The chest radiograph showed bilateral dense alveolo-interstitial infiltrates predominant in the middle and lower lobes (Figure 1). The leukocyte count was $2.8 \mathrm{G} / \mathrm{l}$, with a left shift of 38\%. CRP was $193 \mathrm{mg} / \mathrm{l}$. Other laboratory parameters were in the normal range. Because of a penicillin allergy, the patient was started on levofloxacin. Within the first 24 hours, hypoxemia worsened $\left(\mathrm{PaO}_{2} / \mathrm{FiO}_{2}<\right.$ $100 \mathrm{mmHg}$ ), profound septic shock developed, and the leukocyte count dropped to $0.9 \mathrm{G} / \mathrm{l}$. Sheets of grampositive cocci on sputum stain prompted the addition of vancomycin. A sputum culture grew MSSA. The HIV test was negative. Polymerase chain reaction (PCR) performed on a throat swab was positive for influenza $B$ $(880 \mathrm{cp} / \mathrm{ml})$. The patient remained febrile and a CT scan on the third day revealed extensive infiltrations with cavitations suggestive of multiple abscesses. Suspecting a PVL toxin-secreting strain, antibiotherapy was switched to clindamycin (600 mg qid) and linezolid (600 $\mathrm{mg}$ bid) to downregulate the production of the toxin. High-dose intravenous immunoglobulin $(2 \mathrm{~g} / \mathrm{kg}$ ) was added for 2 days. Within the following 48 hours, fever decreased with marked improvement of the patient's clinical condition and inflammatory parameters. Further characterization of the $S$. aureus strain confirmed PVL production. Despite rapid initial improvement, the patient required prolonged mechanical ventilation and antibiotherapy because of abscess development and several episodes of acute respiratory distress after proximal bronchi obstruction with plugs of necrotic lung tissue (Figure 2). The total duration of clindamycin and linezolid treatment was 29 and 34 days, respectively. The patient was successfully weaned after 31 days of mechanical ventilation and transferred to the medical ward after 38 days in the intensive care unit. He was discharged from the hospital after 50 days. On followup 1 year later, he showed residual dyspnea with heavy exertion but was working again full-time.

\section{Results}

The literature search for MSSA PVL-positive CAP resulted in 31 patient descriptions out of 25 publications 


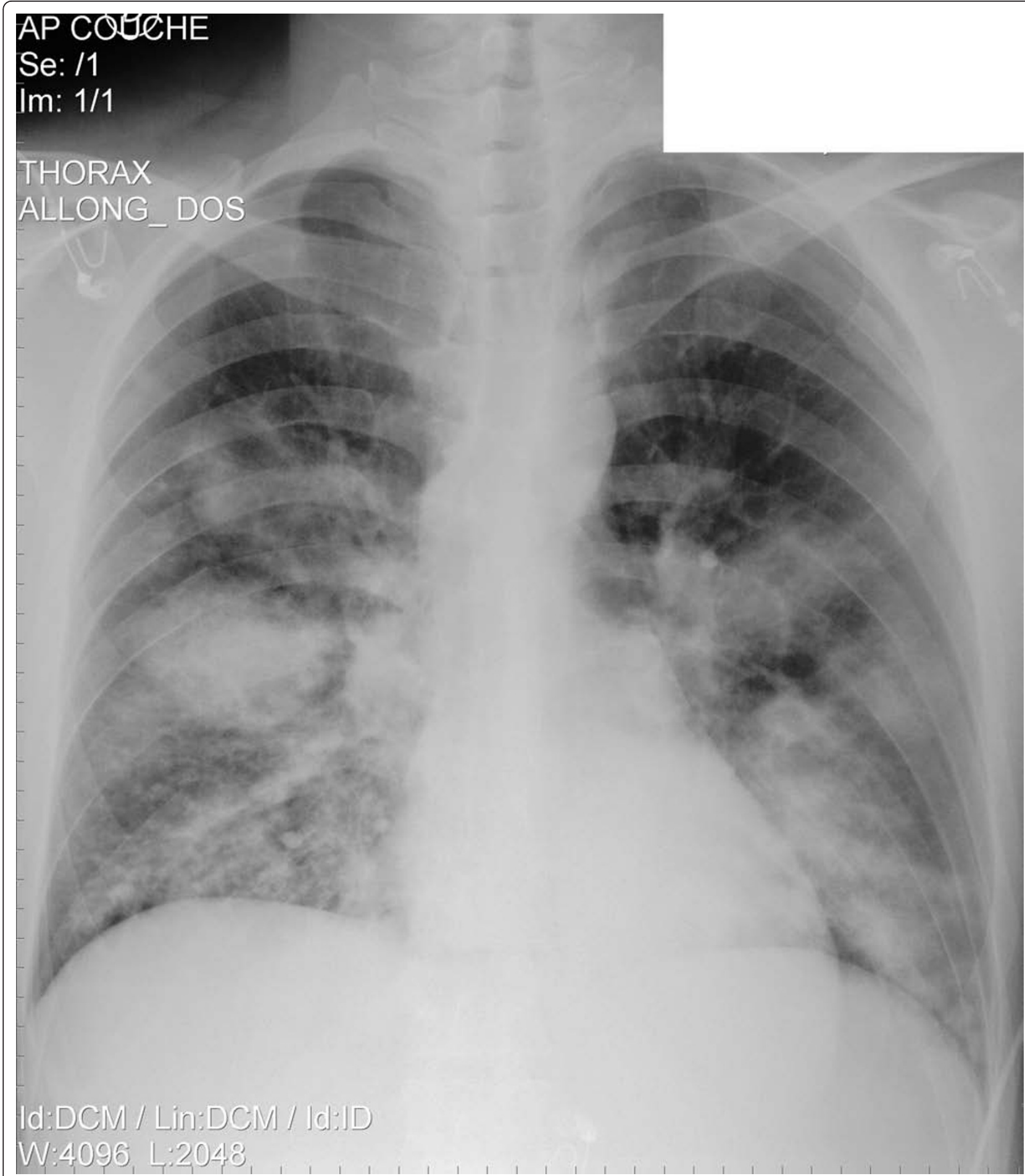

Figure 1 Chest radiograph on admission showing bilateral dense infiltrates.

[5,6,10,13-40]. Twenty-one publications reported European patients, 14 of which were from France. Six publications originated in the United States, three in Asia, and one in Australia. Cases occurred between 1998 and 2009. Most case reports lack detailed data on history, clinical, and laboratory characteristics. Table 1 lists the variables, which were reported often enough to be included in the analysis. Although 93\% of patients (26/ 28) had multilobar pulmonary involvement and were likely to have ARDS, this diagnosis was not used as a 


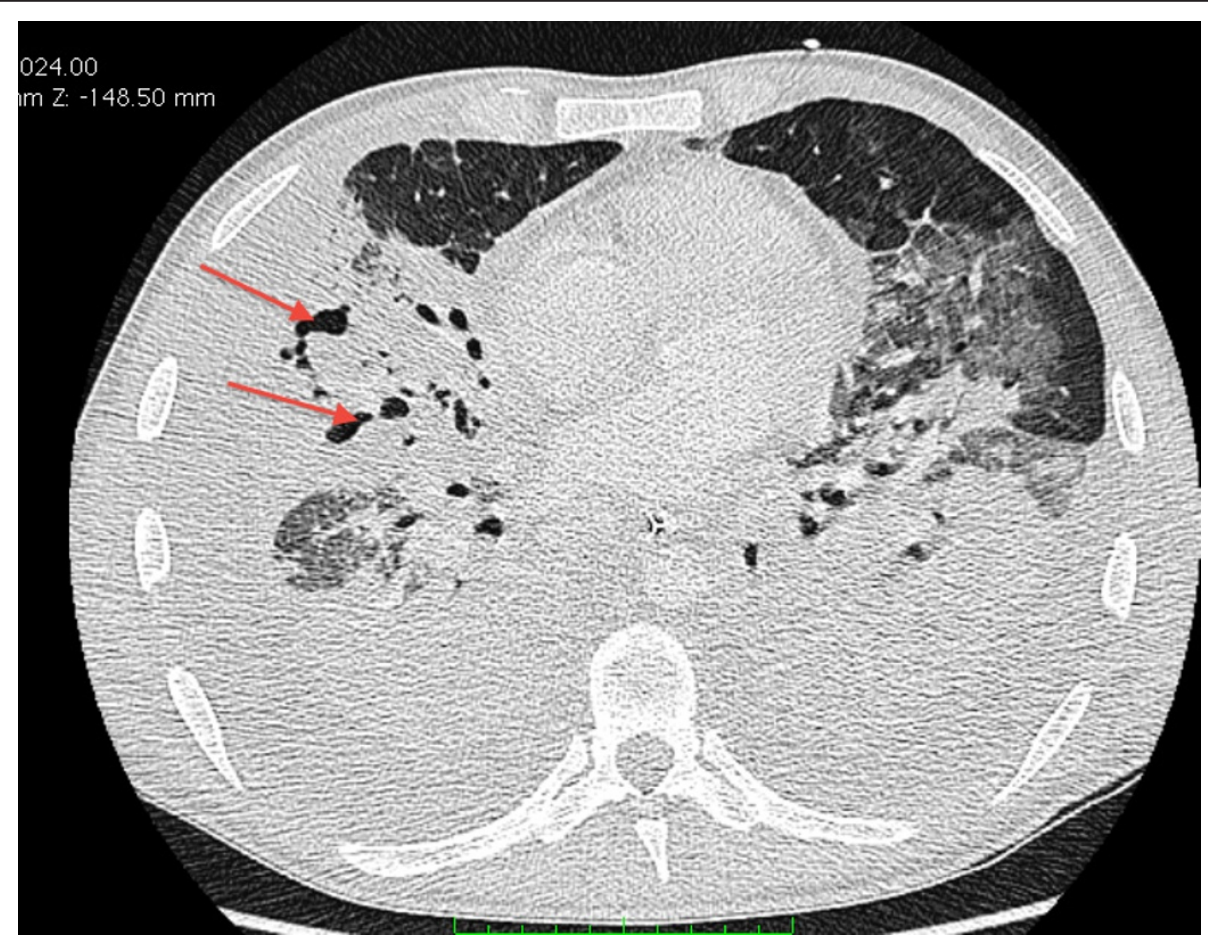

Figure 2 Lung CT scan on day 12 of hospitalization showing abscess formations in the right middle lobe (arrows).

Table 1 Univariate analysis of risk factors associated with mortality in patients with PVL-secreting MSSA-necrotizing CAP

\begin{tabular}{|c|c|c|c|c|}
\hline & $\begin{array}{c}\text { Died } \\
(\mathrm{N}=13)\end{array}$ & $\begin{array}{l}\text { Survived } \\
(\mathrm{N}=19)\end{array}$ & $\begin{array}{c}\text { Univariate analysis } \\
\text { OR }(95 \% \mathrm{Cl})\end{array}$ & $P$ value \\
\hline \multicolumn{5}{|l|}{ Demographics } \\
\hline Age $(y r)$, mean $\pm S D$ & $25.6 \pm 15.5$ & $23.7 \pm 17.2$ & & 0.752 \\
\hline Male gender & $6 / 13(46 \%)$ & $14 / 19(74 \%)$ & $0.31(0.07-1.36)$ & 0.15 \\
\hline \multicolumn{5}{|l|}{ Clinical characteristics } \\
\hline Influenza-like prodrome ${ }^{a}$ & $9 / 12(75 \%)$ & $4 / 16(25 \%)$ & $9.00(1.60-50.7)$ & 0.02 \\
\hline Confirmed influenza coinfection & $0 / 3$ & $3 / 4(75 \%)$ & $0.06(0.002-2.08)$ & 0.143 \\
\hline SSTI on admission & $1 / 13(8 \%)$ & $9 / 19(47 \%)$ & $0.09(0.01-0.86)$ & 0.024 \\
\hline $\mathrm{T}^{\circ}<36^{\circ}$ or $>38^{\circ}$ on admission & $7 / 11(63 \%)$ & 9/11 (82\%) & $0.39(0.05-2.77)$ & 0.635 \\
\hline Multilobar involvement & $12 / 12$ & 14/16 (87\%) & $4.31(0.19-98.6)$ & 0.492 \\
\hline Lower airway hemorrhage $^{\mathrm{b}}$ & $11 / 12(92 \%)$ & $9 / 16(56 \%)$ & $8.56(0.88-83.1)$ & 0.088 \\
\hline Septic shock & 11/11 & $7 / 15(47 \%)$ & $26.0(1.30-522)$ & 0.007 \\
\hline \multicolumn{5}{|l|}{ Laboratory findings } \\
\hline Leukocytopenia & 9/11 (82\%) & $8 / 17(47 \%)$ & $5.06(0.83-30.8)$ & 0.115 \\
\hline Thrombocytopenia & $2 / 8(25 \%)$ & $6 / 6$ & $0.03(0.001-0.75)$ & 0.01 \\
\hline Coagulopathy & 9/9 & $6 / 8(75 \%)$ & $7.31(0.30-178.7)$ & 0.206 \\
\hline Positive blood cultures & $5 / 13(38 \%)$ & $8 / 17(47 \%)$ & $0.56(0.13-2.41)$ & 0.484 \\
\hline \multicolumn{5}{|l|}{ Treatment } \\
\hline Mechanical ventilation & $11 / 12(92 \%)$ & 10/14 (71\%) & $10.7(0.52-223)$ & 0.33 \\
\hline First-line antibiotics targeting toxin production ${ }^{c}$ & $0 / 12$ & $0 / 18$ & - & 1 \\
\hline Intravenous lgG & $1 / 13(8 \%)$ & $5 / 19(26 \%)$ & $0.26(0.03-2.51)$ & 0.361 \\
\hline
\end{tabular}

${ }^{\mathrm{a}}$ Influenza-like syndrome $>48 \mathrm{~h}$ before admission. Symptoms include fever, shivering, chills, malaise, dry cough, loss of appetite, body aches, and nausea.

${ }^{\mathrm{b}}$ Hemoptysis and/or macroscopic blood on bronchoscopy/BAL.

${ }^{\mathrm{c} C l i n d a m y c i n}$, linezolid, or rifampicin,

PVL, Panton-Valentine leukocidin; MSSA, methicillin-sensitive Staphylococcus aureus; CAP, community-acquired pneumonia; SSTI, skin and soft-tissue infection. 
variable because of missing blood gas results and pulmonary wedge pressures.

The average age was 24.5 (interquartile range, 14-38) years, and 13 patients died (41\%). With the exception of one patient who died after 20 days, the median time from admission to death was 20 hours. Univariate analysis found that influenza-like prodrome $(p=0.02)$, absence of skin and soft tissue infection (SSTI) on admission $(p=0.024)$, and septic shock $(p=0.007)$ were associated with death (Table 1). The multivariable model confirmed an association with fatal outcome for influenza-like prodrome (OR, 7.44; 95\% CI, 1.24-44.76; $p$ $=0.028)$ and absent SSTI (OR, 0.09; 95\% CI, 0.01-0.86; $p$ $=0.036)$. Among patients with SSTI, there was a lower rate of preceding influenza-like syndrome $(p=0.0008)$, septic shock $(p=0.014)$, mechanical ventilation $(p=$ $0.047)$, and lower mortality $(p=0.024)$. None of the patients received an initial antibiotherapy targeting the PVL toxin production.

\section{Discussion}

Community-acquired necrotizing pneumonia due to $S$. aureus-secreting PLV toxin is a highly lethal infection, affecting a young and healthy population group [5]. The hallmarks are an influenza-like prodrome, leukopenia, rapid progression to septic shock, and respiratory distress, with multilobar necrosis and haemoptysis $[5,6,14]$.

In this series, the mortality rate was $41 \%$, which is lower than most of previously published rates $[3,5,14,15]$. On multivariable analysis, influenza-like prodrome predicted fatal outcome. The true proportion of influenza infection is difficult to assess, because influenza testing is not routinely performed and rapid test sensitivity is only $50-70 \%$ [41]. Influenza impedes phagocytic killing and damages the trachea-bronchial epithelium with subsequent impairment of secretion clearance and facilitated bacterial adhesion [42-44]. The influenzalike prodrome also may be caused by other respiratory viruses or by $S$. aureus itself.

We found a significant reduction of mortality for patients with skin and soft-tissue infection on admission. This result is new in the context of PVL-associated $S$. aureus necrotizing pneumonia, although one study mentioned a nonsignificant trend toward lower mortality for patients with a history of furuncles [6] and a recent retrospective study found a significant protective effect of a history of PVL-associated infections [45]. Similar results also have been published in studies on $S$. aureus carriers. Approximately $20-30 \%$ of healthy persons are persistently colonized with $S$. aureus $[44,46]$. When hospitalized, these carriers have an increased risk of developing severe $S$. aureus infection caused by their colonizing strain [47], but mortality of $S$. aureus bacteremia is much lower in carriers than in noncarriers [48]. The likely explanation for this protective effect is the stimulation of an immune response, which lowers the intensity of a subsequent invasive infection [49]. A PVL vaccine has already been successfully tested on mice models and may find a human application in the near future [50].

Another issue raised by this study is the high rate of inadequate initial antibiotic treatment regimens. None of the 32 published cases received an antibiotic with an antitoxin effect as part of their first-line treatment, and all but three patients received beta-lactams. The use of beta-lactams as first-line treatment is controversial, because drug levels below the minimum inhibitory concentration may increase toxin release and stimulate toxin production $[37,38,51]$. The former effect is due to release of intracellular toxin secondary to cell wall lysis. In vivo, low drug levels in target tissues are a consequence of extensive tissue necrosis, leading to poor antibiotic diffusion and a sepsis-related increase of the volume of distribution. However, the stimulatory effect on toxin release is reversed when beta-lactams are given in association with clindamycin, linezolid, or rifampicin [52]. The high rate of inadequate initial antibiotic treatment may be explained by the low prevalence of necrotizing S. aureus pneumonia, the low specificity of initial clinical signs and symptoms, and the adherence to treatment guidelines for community-acquired pneumonias. However, even after overt clinical suspicion or microbiological confirmation of PVL-secreting S. aureus, only $36 \%(5 / 14)$ of second-line antibiotics were adequate. Not surprisingly, the rate of adequacy was higher among more recent case reports. Since 2007, the Infectious Diseases Society of America (IDSA) recommends adding vancomycin or linezolid in case of severe pneumonia due to CA-MRSA [53]. In the United Kingdom, the Health Protection Agency (HPA) recommends a combination of clindamycin, linezolid, and rifampicin but explicitly dissuades from the use of beta-lactams [54]. Based on the discussed in vitro findings for beta-lactams, a recent recommendation by Gillet et al. suggests a third-generation cephalosporin with vancomycin and clindamycin or linezolid as first-line antibiotherapy. In the case of MSSA, vancomycin can be replaced by oxacillin [55].

Intravenous immunoglobulin may be an important adjunct to antibiotherapy. As illustrated in the above and in other case reports, it has been used successfully on a sporadic basis $[30,36,56]$. It was studied in vitro and was shown to neutralize PVL-induced pore formation and cytopathic effect [57]. The HPA recommends intravenous immunoglobulin at a dose of $2 \mathrm{~g} / \mathrm{kg}$ to be repeated after 48 hours if there is persistence of septic shock or failure to respond [54]. 
The significance of our study results is limited by its reliance on a relatively small number of case reports. Also, many variables, such as thrombocytopenia or kidney function, were reported infrequently and thus could not be included in the statistical analysis. We suspect that only the most severe cases of CAP caused by PVLsecreting MSSA are reported and that many cases are not detected, making it difficult to describe the full spectrum of clinical illness and to form meaningful conclusions based on the case reports. To improve our knowledge of the epidemiology, diagnosis, and treatment, there is a need to establish an international database.

\section{Conclusions}

Necrotizing pneumonia due to PVL-secreting S. aureus mandates prompt recognition and specific treatment to prevent premature death in immunocompetent patients. Early suspicion should be triggered by the presence of influenza-like prodrome, leucopenia, rapid progression to septic shock, respiratory distress with multilobar necrosis, and hemoptysis. For PVL-secreting MSSAnecrotizing pneumonia, influenza-like prodrome may be associated with fatal outcome, whereas previous SSTI may reduce mortality. Further studies based on a larger patient number are necessary to confirm this finding.

\section{Author details \\ ${ }^{1}$ Department of Anaesthesiology, Hôpitaux Universitaires de Genève (HUG), Geneva, Switzerland ${ }^{2}$ Keenan Research Centre, Li Ka Shing Knowledge Institute St. Michael's Hospital, Toronto, Canada ${ }^{3}$ Department of Intensive Care, Centre Hospitalier Universitaire Vaudois (CHUV), and University of Lausanne, Switzerland}

\section{Authors' contributions}

LK and PE conceived the study and wrote the manuscript. EC provided data statistics and participated in data interpretation and final writing. All authors read and approved the final manuscript.

\section{Competing interests}

The authors declare that they have no competing interests.

Received: 20 September 2011 Accepted: 22 December 2011

Published: 22 December 2011

\section{References}

1. Howard LS, Sillis M, Pasteur MC, Kamath AV, Harrison BD: Microbiological profile of community-acquired pneumonia in adults over the last 20 years. J Infect 2005, 50:107-113.

2. Chickering HT, Park JH Jr: Staphylococcus aureus pneumonia. JAMA 1919, 72:617-626

3. Kallen AJ, Brunkard J, Moore Z, Budge P, Arnold KE, Fosheim G, Finelli L, Beekmann SE, Polgreen PM, Gorwitz R, Hageman J: Staphylococcus aureus community-acquired pneumonia during the 2006 to 2007 influenza season. Ann Emerg Med 2009, 53:358-365.

4. Lina G, Piemont Y, Godail-Gamot F, Bes M, Peter MO, Gauduchon V, Vandenesch F, Etienne J: Involvement of Panton-Valentine leukocidinproducing Staphylococcus aureus in primary skin infections and pneumonia. Clin Infect Dis 1999, 29:1128-1132

5. Gillet $Y$, Issartel B, Vanhems $P$, Fournet JC, Lina $G$, Bes M, Vandenesch F, Piémont $Y$, Brousse $N$, Floret $D$, Etienne J: Association between
Staphylococcus aureus strains carrying gene for Panton-Valentine leukocidin and highly lethal necrotising pneumonia in young immunocompetent patients. Lancet 2002, 359:753-759.

6. Gillet $Y$, Vanhems $P$, Lina $G$, Bes $M$, Vandenesch F, Floret D, Etienne J: Factors predicting mortality in necrotizing community-acquired pneumonia caused by Staphylococcus aureus containing PantonValentine leukocidin. Clin Infect Dis 2007, 45:315-321.

7. Miles G, Movileanu L, Bayley H: Subunit composition of a bicomponent toxin: staphylococcal leukocidin forms an octameric transmembrane pore. Protein Sci 2002, 11:894-902.

8. Bubeck WJ, Palazzolo-Ballance AM, Otto M, Schneewind O, DeLeo FR: Panton-Valentine leukocidin is not a virulence determinant in murine models of community-associated methicillin-resistant Staphylococcus aureus disease. J Infect Dis 2008, 198:1166-1170.

9. Olsen RJ, Kobayashi SD, Ayeras AA, Ashraf M, Graves SF, Ragasa W, Humbird T, Greaver JL, Cantu C, Swain JL, Jenkins L, Blasdel T, Cagle PT, Gardner DJ, DeLeo FR, Musser JM: Lack of a major role of Staphylococcus aureus Panton-Valentine leukocidin in lower respiratory tract infection in nonhuman primates. Am J Pathol 2010, 176:1346-1354.

10. Hidron Al, Low CE, Honig EG, Blumberg HM: Emergence of communityacquired meticillin-resistant Staphylococcus aureus strain USA300 as a cause of necrotising community-onset pneumonia. Lancet Infect Dis 2009, 9:384-392.

11. Moran GJ, Krishnadasan A, Gorwitz RJ, Fosheim GE, McDougal LK, Carey RB, Talan DA: Methicillin-resistant $\mathrm{S}$. aureus infections among patients in the emergency department. N Engl J Med 2006, 355:666-674.

12. Health Protection Agency: PLV-Staphylococcus aureus infections: an update. Health protection report 2011, 5, News Archives.

13. Rasigade JP, Laurent F, Lina G, Meugnier H, Bes M, Vandenesch F, Etienne J, Tristan A: Global distribution and evolution of Panton-Valentine leukocidin-positive methicillin-susceptible Staphylococcus aureus, 1981 2007. J Infect Dis 2010, 201:1589-1597.

14. Vardakas KZ, Matthaiou DK, Falagas ME: Comparison of communityacquired pneumonia due to methicillin-resistant and methicillinsusceptible Staphylococcus aureus producing the Panton-Valentine leukocidin. Int J Tuberc Lung Dis 2009, 13:1476-1485.

15. Li HT, Zhang TT, Huang J, Zhou YQ, Zhu JX, Wu BQ: Factors associated with the outcome of life-threatening necrotizing pneumonia due to community-acquired Staphylococcus aureus in adult and adolescent patients. Respiration 2011, 81:448-460.

16. Alonso-Tarres C, Villegas ML, de Gispert FJ, Cortes-Lletget MC, Rovira PA, Etienne J: Favorable outcome of pneumonia due to Panton-Valentine leukocidin-producing Staphylococcus aureus associated with hematogenous origin and absence of flu-like illness. Eur J Clin Microbiol Infect Dis 2005, 24:756-759.

17. Barcelo M, Chauvet E, Boukhari R, Mbieleu B: [Staphylococcic necrotizing pneumopathy due to Panton-Valentine leukocidin toxin with good outcome]. Arch Pediatr 2009, 16:32-36.

18. Beilouny B, Ciupea A, Eloy C, Simon G: Fatal community-acquired pneumonia due to Staphylococcus aureus carrying Panton-Valentine leukocidin genes after a stay in Africa. Intensive Care Med 2008, 34:388-389.

19. Boussaud V, Parrot A, Mayaud C, Wislez M, Antoine M, Picard C, Delisle F, Etienne J, Cadranel J: Life-threatening hemoptysis in adults with community-acquired pneumonia due to Panton-Valentine leukocidinsecreting Staphylococcus aureus. Intensive Care Med 2003, 29:1840-1843.

20. Chetchotisakd P, Anunnatsiri S, Puapermpoonsiri S, Prariyachatgul C, Chumpol J: A rapidly fatal case of Panton-valentine leukocidin positive Staphylococcus aureus necrotizing pneumonia in an HIV-infected patient. Southeast Asian J Trop Med Public Health 2007, 38:690-694.

21. Elizur A, Orscheln RC, Ferkol TW, Dunne WM Jr, Storch GA, Cannon CL: Transmission of Panton-Valentine leukocidin-positive Staphylococcus aureus between patients with cystic fibrosis. J Pediatr 2007, 151:90-92

22. Honapour N, Mao JT: A case of fatal community-acquired necrotizing pneumonia caused by Panton-Valentine leukocidin positive methicillinsensitive Staphylococcus aureus. Curr Respir Med Rev 2007, 3:49-51.

23. Hörnig-Franz I, Kahl C, Tebbe W, Kersting C, Bürger H, Nolte K, Becker K, Bulla M, Debus O, Rabe H, Harms E: Nekrotisierende Pneumonie mit Staphylococcus aureus (pvl-Gen positiv). Monatsschrift Kinderheilkunde 2007, 155(S01):S10-S15. 
24. Hsu LY, Koh TH, Anantham D, Kurup A, Chan KP, Tan BH: Panton-Valentine leukocidin-positive Staphylococcus aureus, Singapore. Emerg Infect Dis 2004, 10:1509-1510.

25. Hyvernat H, Pulcini C, Carles D, Roques A, Lucas P, Hofman V, Bernardin G: Fatal Staphylococcus aureus haemorrhagic pneumonia producing Panton-Valentine leucocidin. Scand J Infect Dis 2007, 39:183-185.

26. Klein JL, Petrovic Z, Treacher D, Edgeworth J: Severe community-acquired pneumonia caused by Panton-Valentine leukocidin-positive Staphylococcus aureus: first reported case in the United Kingdom. Intensive Care Med 2003, 29:1399.

27. Laifer G, Frei R, Adler H, Fluckiger U: Necrotising pneumonia complicating a nasal furuncle. Lancet 2006, 367:1628

28. Laporte-Turpin E, Marcoux MO, Claudet I, Grouteau E, Micheau P, Federici S, Alberge C, Prère MF: [Necrotizing pneumonia and arthritis due to Staphylococcus aureus producing Panton and Valentine leukocidin in a 10-year-old boy]. Arch Pediatr 2006, 13:449-452.

29. Le T, Mariani-Kurkdjian P, Collignon A, Gravet A, Clermont O, Brahimi N, Gaudelus J, Aujard Y, Navarro J, Beaufils F, Bingen E: Breast milk transmission of a Panton-Valentine leukocidin-producing Staphylococcus aureus strain causing infantile pneumonia. J Clin Microbiol 2001, 39:728-729.

30. Libert N, Borne M, Janvier F, Batjom E, Cirodde A, Nizou JY, Bringuin L: [Successful treatment of life-threatening Panton-Valentine leucocidin positive Staphylococcus aureus pneumonia with antibiotics and immunoglobulins targeting the toxin production]. Rev Med Interne 2009, 30:907-910.

31. Low TB, Harty L, Murray M, Andrews C, O'Neill SJ: Panton Valentine leukocidin MSSA leading to multi-organ failure. Ir Med J 2009, 102:185.

32. Miyashita $T$, Shimamoto $Y$, Nishiya $H$, Koshibu $Y$, Sugiyama $H$, Ono $Y$, Satoh T, Haraoka H, Nakano J, Ohta K: Destructive pulmonary embolism in a patient with community-acquired staphylococcal bacteremia. J Infect Chemother 2002, 8:99-102.

33. Mongkolrattanothai K, Boyle S, Kahana MD, Daum RS: Severe Staphylococcus aureus infections caused by clonally related communityacquired methicillin-susceptible and methicillin-resistant isolates. Clin Infect Dis 2003, 37:1050-1058.

34. Mushtaq F, Hildrew S, Okugbeni G, Ellis RW, Deshpande S: Necrotizing haemorrhagic pneumonia proves fatal in an immunocompetent child due to Panton-Valentine Leucocidin, toxic shock syndrome toxins 1 and 2 and enterotoxin C-producing Staphylococcus aureus. Acta Paediatr 2008, 97:985-987.

35. Roberts JC, Gulino SP, Peak KK, Luna VA, Sanderson R: Fatal necrotizing pneumonia due to a Panton-Valentine leukocidin positive communityassociated methicillin-sensitive Staphylococcus aureus and Influenza coinfection: a case report. Ann Clin Microbiol Antimicrob 2008, 19;7(5):5.

36. Rouzic N, Janvier F, Libert $N$, Javouhey E, Lina G, Nizou JY, Pasquier $P$, Stamm D, Brinquin L, Pelletier C, Vandenesch F, Floret D, Etienne J, Gillet Y: Prompt and successful toxin-targeting treatment of three patients with necrotizing pneumonia due to Staphylococcus aureus strains carrying the Panton-Valentine leukocidin genes. J Clin Microbiol 2010, 48:1952-1955.

37. Salliot C, Zeller V, Puechal X, Manceron V, Sire S, Varache N, Etienne J, Desplaces N, Ziza JM: Panton-Valentine leukocidin-producing Staphylococcus aureus infections: report of 4 French cases. Scand J Infect Dis 2006, 38:192-195.

38. Schefold JC, Esposito F, Storm C, Heuck D, Kruger A, Jorres A, Witte W, Hasper D: Therapy-refractory Panton Valentine Leukocidin-positive community-acquired methicillin-sensitive Staphylococcus aureus sepsis with progressive metastatic soft tissue infection: a case report. J Med Case Rep 2007, 1:165

39. Swaminathan A, Massasso D, Gotis-Graham I, Gosbell I: Fulminant methicillin-sensitive Staphylococcus aureus infection in a healthy adolescent, highlighting 'Panton-Valentine leucocidin syndrome'. Intern Med J 2006, 36:744-747.

40. Wenzel JJ, Hentschel J, Silvis W, Permanetter W, Mattes J, Kochanowski B et Heterich R, Jilg W, Linde HJ: Rapidly fatal necrotizing pneumonia in a 12year-old boy caused by co-infection with parainfluenza virus type 1 and Panton-Valentine leukocidin (PVL)-positive methicillin-sensitive Staphylococcus aureus. Infection 2009, 37:75-77.

41. Ebell $\mathrm{MH}$, Afonso $\mathrm{A}$ : A systematic review of clinical decision rules for the diagnosis of influenza. Ann Fam Med 2011, 9:69-77.
42. Lee MH, Arrecubieta C, Martin FJ, Prince A, Borczuk AC, Lowy FD: A postinfluenza model of Staphylococcus aureus pneumonia. J Infect Dis 2010, 201:508-515.

43. Shornick LP, Wells AG, Zhang Y, Patel AC, Huang G, Takami K, Sosa M, Shukla NA, Agapov E, Holtzman MJ: Airway epithelial versus immune cell Stat 1 function for innate defense against respiratory viral infection. $J$ Immunol 2008, 180:3319-3328.

44. Mertz D, Frei R, Periat N, Zimmerli M, Battegay M, Widmer AF: Exclusive Staphylococcus aureus throat carriage: at-risk populations. Arch Intern Med 2009, 169:172-178.

45. Rasigade JP, Sicot N, Laurent F, Lina G, Vandenesch F, Etienne J: A history of Panton-Valentine leukocidin (PVL)-associated infection protects against death in PVL-associated pneumonia. Vaccine 2011, 29:4185-4186.

46. Acton DS, Plat-Sinnige MJ, van Wamel W, de Groot N, van Belkum A: Intestinal carriage of Staphylococcus aureus: how does its frequency compare with that of nasal carriage and what is its clinical impact? Eur J Clin Microbiol Infect Dis 2009, 28:115-127.

47. von Eiff C, Becker K, Machka K, Stammer H, Peters G: Nasal carriage as a source of Staphylococcus aureus bacteremia. Study Group. N Engl J Med 2001, 344:11-16.

48. Wertheim HF, Melles DC, Vos MC, van Leeuwen W, van Belkum A, Verbrugh HA, Nouwen $J$ L: The role of nasal carriage in Staphylococcus aureus infections. Lancet Infect Dis 2005, 5:751-762.

49. Noel C, Florquin S, Goldman M, Braun MY: Chronic exposure to superantigen induces regulatory CD4(+) T cells with IL-10-mediated suppressive activity. Int Immunol 2001, 13:431-439.

50. Brown EL, Dumitrescu O, Thomas D, Badiou C, Koers EM, Choudhury P, Vazquez V, Etienne J, Lina G, Vandenesch F, Bowden MG: The PantonValentine leukocidin vaccine protects mice against lung and skin infections caused by Staphylococcus aureus USA300. Clin Microbiol Infect 2009, 15:156-164.

51. Stevens DL, Ma Y, Salmi DB, McIndoo E, Wallace RJ, Bryant AE: Impact of antibiotics on expression of virulence-associated exotoxin genes in methicillin-sensitive and methicillin-resistant Staphylococcus aureus. Infect Dis 2007, 195:202-211.

52. Dumitrescu O, Badiou C, Bes M, Reverdy ME, Vandenesch F, Etienne J, Lina G: Effect of antibiotics, alone and in combination, on PantonValentine leukocidin production by a Staphylococcus aureus reference strain. Clin Microbiol Infect 2008, 14:384-388.

53. Mandell LA, Wunderink RG, Anzueto A, Bartlett JG, Campbell GD, Dean NC, Dowell SF, File TM Jr, Musher DM, Niederman MS, Torres A, Whitney CG: Infectious Diseases Society of America/American Thoracic Society consensus guidelines on the management of community-acquired pneumonia in adults. Clin Infect Dis 2007, 44(Suppl 2):S27-S72.

54. Health Protection Agency: 2 2008, Guidance on the diagnosis and management of PVL-associated Staphylococcus aureus infections (PVL-SA) in England.

55. Gillet Y, Dumitrescu O, Tristan A, Dauwalder O, Javouhey E, Floret D, Vandenesch F, Etienne J, Lina G: Pragmatic management of PantonValentine leukocidin-associated staphylococcal diseases. Int J Antimicrob Agents 2011, 38:457-464.

56. Adem PV, Montgomery CP, Husain AN, Koogler TK, Arangelovich V, Humilier M, Boyle-Vavra S, Daum RS: Staphylococcus aureus sepsis and the Waterhouse-Friderichsen syndrome in children. N Engl J Med 2005, 353:1245-1251

57. Gauduchon V, Cozon G, Vandenesch F, Genestier AL, Eyssade N, Peyrol S, Etienne J, Lina G: Neutralization of Staphylococcus aureus Panton Valentine leukocidin by intravenous immunoglobulin in vitro. $J$ Infect Dis 2004, 189:346-353.

doi:10.1186/2110-5820-1-52

Cite this article as: Kreienbuehl et al:: Community-acquired necrotizing pneumonia due to methicillin-sensitive Staphylococcus aureus secreting Panton-Valentine leukocidin: a review of case reports. Annals of Intensive Care 2011 1:52 